\title{
Evaluation of malignant parathyroid tumours in two European cohorts of patients with sporadic primary hyperparathyroidism
}

\author{
Arturs Ozolins $^{1} \cdot$ Zenons Narbuts $^{1} \cdot$ Andrejs Vanags $^{1} \cdot$ Zane Simtniece $^{2}$. \\ Zane Visnevska $^{1}$ - Aycan Akca ${ }^{3}$. Denis Wirowski ${ }^{3}$. \\ Janis Gardovskis ${ }^{1} \cdot$ Ilze Strumfa $^{2} \cdot$ Peter E. Goretzki $^{3}$
}

Received: 21 September 2015 /Accepted: 29 November 2015 /Published online: 11 December 2015

(C) The Author(s) 2015. This article is published with open access at Springerlink.com

\begin{abstract}
Purpose Parathyroid carcinoma $(\mathrm{PC})$ is remarkable for its rare occurrence and challenging diagnostics. PC accounts for $0.1-$ $5 \%$ cases of primary hyperparathyroidism (PHPT). The differentiation from benign tumours is difficult even by morphological criteria. To address these issues, we assessed the PC frequency in two separate European PHPT cohorts and evaluated the demographic, clinical, morphological and molecular background.

Methods A retrospective study was carried out, using continuously maintained database (2005-2014) of PHPT patients from two tertiary referral university hospitals in Europe. The demographic, clinical data and frequency of PC among surgically treated PHPT was detected. Immunohistochemistry (IHC) was performed to detect parafibromin, representing protein product of HRPT2 gene and proliferation marker Ki-67. Results Both PHPT cohorts were characterised by close mean age values (58.6 and 58.0 years) and female predominance. The frequency of PC differed significantly between the cohorts: 2.1 vs. $0.3 \% ; p=0.004$. PC was characterised by invariable complete loss of parafibromin contrasting with parathyroid adenomas. The proliferation fraction was similar in both PC cohorts (10.6 and $11.0 \%)$. PC showed significantly higher proliferation fraction than typical parathyroid adenomas
\end{abstract}

Arturs Ozolins

arturs.ozolins@rsu.lv

1 Department of Surgery, Riga Stradins University, Dzirciema Street 16, LV-1007 Riga, Latvia

2 Department of Pathology, Riga Stradins University, Riga, Latvia

3 Department of Surgery, Lukas Hospital, Neuss, Germany
$(1.6 \%)$, atypical adenomas $(1.6 \%)$ or adenomas featuring focal loss of parafibromin $(2.2 \%)$.

Conclusions PC frequency can range significantly between the two European cohorts. The differences can be attributable to selection bias of patients referred for surgery and are not caused by discordant definition of malignant parathyroid histology. Diffuse loss of parafibromin and increased proliferation fraction by Ki-67 are valuable adjuncts in PC diagnostics due to significant differences with various clinical and morphological subtypes of adenoma.

Keywords Parathyroid carcinoma $\cdot$ Primary hyperparathyroidism $\cdot$ Immunohistochemistry . Ki-67 · Parafibromin

\section{Introduction}

Primary hyperparathyroidism (PHPT) is among the most common endocrine diseases. It usually results from a single parathyroid adenoma (PA). Less frequently, tumours can develop in multiple parathyroid glands [1]. Parathyroid carcinoma (PC) is the least common endocrine malignancy representing only $0.005 \%$ of all cancers [2]. PC accounts for $0.1-5 \%$ of all PHPT in contrary to benign PA causing approximately $85 \%$ of PHPT cases [3]. Around half of PC cases are diagnosed at a mean age of 50 years with no sex or race predilection [4]. Most of the patients present with clinical and biochemical manifestations of severe hyperparathyroidism, including severe hypercalcemia, elevated parathyroid hormone (PTH) level as well as renal and osseous complications [5]. A palpable neck mass is present in 30-76\% of patients [4]. However, the diagnosis of PC is rarely made preoperatively. 
Aetiology of PC is largely unknown but history of neck irradiation is a known risk factor for all neck cancers. There is no evidence that $\mathrm{PC}$ arises from pre-existing benign parathyroid lesions [4]. PC can occur sporadically and in $15 \%$ of cases in association with familial isolated primary hyperparathyroidism and hyperparathyroidism-jaw tumour syndrome (HPT-JT). This is not the case for other syndromes like multiple endocrine neoplasia (MEN1, MEN2A) [3, 6].

Intraoperatively, malignant nature is suspected by the features of local invasion, as well as enlarged and firm to hard affected gland with greyish white cut surface. The mean tumour size reaches approximately $3 \mathrm{~cm}$ (range, 1$7 \mathrm{~cm}$ ), and the average weight ranges around $3 \mathrm{~g}$. However, tumours as large as $67 \mathrm{~g}$ have been reported $[5,7]$. The diagnosis of PC must be confirmed by the World Health Organisation (WHO) morphological criteria. Extensive invasion of adjacent tissues and metastatic spread represent the two absolute diagnostic criteria [8]. The other criteria include focal coagulation necrosis, irregular dense fibrosis and capsular, vascular or neural invasion. PC most frequently invades the ipsilateral thyroid ( $89 \%)$, skeletal muscles $(71 \%)$, recurrent laryngeal nerve $(26 \%)$, oesophagus $(18 \%)$ as well as trachea in $17 \%$ of PC patients [9]. Since parathyroids can be located inside the thyroid gland, the mere presence of parathyroid tissue within the thyroid is not sufficient for diagnosing parathyroid carcinoma. Regional metastases are present in $15 \%$ of cases. Distal metastases in the lungs and bones are rare $[9,10]$.

Despite the refined morphological criteria, the diagnosis of PC remains challenging. Over the last decades, physicians, surgeons and pathologists have experienced difficulties in distinguishing PC from benign disease if the patient was lacking overt invasion and/or metastasis [11]. Among advances in the knowledge of the molecular pathogenesis of PC, the identification of the tumour suppressor gene HRPT2 and the relevant protein, parafibromin have resulted in a valuable diagnostic tool. HRPT2 mutations result in loss of parafibromin that can be assessed by immunohistochemistry - a widely available and cheap tissue investigation technique [12]. The proliferation marker Ki-67 has also been characterised as a useful tool, since PC usually has greater Ki-67 expression than adenomas [13, 14]. However, both groups overlap; therefore, the current WHO classification guidelines suggest that patients having Ki-67 expression in more than $5 \%$ of parathyroid tumour cells should not be diagnosed with clear-cut cancer but instead should be followed closer due to an increased risk of malignant course [14].

To address the urgent epidemiological and diagnostic issues, we assessed the PC frequency in two separate European PHPT cohorts and evaluated the demographic, clinical, morphological and molecular background.

\section{Materials and methods}

\section{Study design}

The study was performed as a retrospective investigation, using continuously supplemented database of parathyroidectomies. The database was surgeon-maintained at two tertiary referral university hospitals-Pauls Stradins Clinical university hospital, Riga (Latvia) and Lukas hospital, Neuss (Germany). Patients who were diagnosed with PHPT and underwent surgical treatment (2005-2014) were identified within the databases. The inclusion criteria comprised a verified morphological diagnosis of a parathyroid tumour in a surgically removed tissue material. Patients with positive family history of PHPT, secondary or tertiary hyperparathyroidism were excluded from further analysis. Thus, 982 patients were eligible for the study, including 288 patients from Latvia and 694 from Germany. The data on the final diagnosis, age at the time of operation, sex, main clinical symptoms, preoperative serum calcium $(\mathrm{Ca})$ and PTH levels were retrieved. The frequency of PC among surgically treated PHPT was detected and compared between the two European cohorts. Further, data of patients with proven PC were compared to patients who underwent surgery for benign PHPT.

\section{Surgical pathology evaluation}

A retrospective morphological and immunohistochemical investigation of consecutive surgically treated parathyroid tumours was carried out. The pathology data have been obtained via uniform, protocol-based gross and microscopic examination of the parathyroid surgery materials. Grossly, the largest diameter of a mass lesion was detected, among other findings. The tissues were sampled widely for microscopic examination including multiple sections from the tumour capsule and/or grossly involved adjacent thyroid or soft tissues. The samples were routinely fixed in neutral buffered formalin, processed, embedded in paraplast, cut in 3- $\mu \mathrm{m}$ thickness and stained with haematoxylin and eosin. The slides were examined under light microscopy to detect histological tumour type in accordance with the following criteria.

PC was diagnosed either by any one of definitive criteria, or on the basis of at least three additional criteria. The definitive criteria of PC comprised unequivocal evidence of invasive growth involving the surrounding tissues as the thyroid gland, soft tissues or oesophagus; or vascular or perineural invasion; or the presence of regional or distant metastases. The additional criteria included capsular invasion, mitotic activity exceeding five mitoses/ten high power fields, broad fibrotic bands splitting the tumour parenchyma into nodules, coagulative necrosis, diffuse sheet-like monotonous small cells with high nuclear/cytoplasmic ratio, diffuse cellular 
atypia and widespread nucleolomegaly. If at least three of these features were present, the tumour was diagnosed as carcinoma; otherwise, the diagnosis of atypical PA was issued. PA was diagnosed on the basis of bland non-hyperplastic morphology [15-17].

\section{Immunohistochemical visualisation and assessment}

Immunohistochemistry (IHC) was performed on representative blocks of tumour tissues. For IHC, 3- $\mu$ m sections were cut on electrostatic glass slides (Histobond, Marienfeld, Germany). After deparaffinisation, antigen retrieval was performed in a microwave oven $(3 \times 5 \mathrm{~min})$ using a basic $(\mathrm{pH} 9.0)$ tris (hydroxymethyl) aminomethane/ethylenediaminetetraacetic acid (Tris/EDTA) buffer (DAKO, Glostrup, Denmark). After the activity of endogenous peroxidase was blocked, the sections were incubated with primary antibodies for $60 \mathrm{~min}$ in the magnetic incubation tray at room temperature. To detect the proliferation activity by $\mathrm{Ki}-67$ expression, monoclonal mouse antibody against human antigen, clone MIB-1 (DAKO), was applied at the dilution 1:100. To detect the expression of parafibromin, representing the protein product of HRPT2 gene, polyclonal rabbit antibody against human antigen (Abcam; code ab84916) was used at the dilution 1:500. The bound primary antibodies were detected by the enzyme-conjugated polymeric visualisation system EnVision (DAKO), linked with horseradish peroxidase using 3,3'-diaminobenzidine as the chromogen (DAKO). Positive and negative quality controls were invariably performed and reacted appropriately. Parafibromin expression was evaluated as a categorical variable. A case was considered positive if unequivocal nuclear reactivity was present in tumour cells; otherwise, the case was treated as negative [18]. To characterise the expression of Ki-67 by mean proliferation fraction, positive nuclei were counted in 400 consecutive neoplastic cells, and the result was expressed as the percentage. Computed-assisted morphometry was applied for quantitative measurements of nuclear positivity, using NIS-Elements (Nikon, Tokyo, Japan) software to analyse im- ages that were obtained by. Eclipse Ci-L microscope (Nikon) in association with DS-Fi2 camera (Nikon).

The immunophenotype was compared among three clinically distinct categories of parathyroid tumours: (1) PC, (2) atypical adenoma possessing atypical morphology but not fulfilling PC criteria and associated with high preoperative $\mathrm{Ca}$ level exceeding $2.9 \mathrm{mmol} / \mathrm{l}$ and high preoperative PTH exceeding $250 \mathrm{pg} / \mathrm{ml}$ and (3) typical PA lacking all the previously listed features.

\section{Statistical analysis}

The statistical evaluation of the data was carried out using the Statistical Package for Social Sciences (SPSS ${ }^{\circledR}$ version 20) software. In addition, CIA software was used to detect the $95 \%$ confidence interval $(\mathrm{CI})$ as described by Altman et al. [19]. Differences were considered statistically significant if $p<0.05$.

\section{Results}

The database search yielded 982 eligible patients. The demographic data and clinical features of the PHPT cohorts from Pauls Stradins Clinical university hospital, Riga (LAT) and Lukas hospital, Neuss (GER) are shown in Table 1. Regarding age, there was no difference between the two European cohorts. Females were predominantly affected in both groups. However, the female-to-male ratio differed statistically significantly ( $p=0.006$ ), as it was 7:1 in LAT group vs 4:1 among GER patients.

The mean preoperative $\mathrm{Ca}$ and PTH levels were significantly higher in LAT group compared to those in GER ( $p=$ $0.01 ; p=0.001$, respectively) (Table 1 ). Preoperative Ca concentration exceeded $2.9 \mathrm{mmol} / 1$ in $35.1 \%$ (95 \% CI=29.840.8) of LAT cases vs $32.0 \%$ (95 \% CI=28.6-35.6) GER patients. Preoperative PTH level exceeded $250 \mathrm{pg} / \mathrm{ml}$ in $28.5 \%(95 \% \mathrm{CI}=23.6-34.0)$ of LAT vs $16.0 \%(95 \% \mathrm{CI}=$
Table 1 Demographic data and clinical features of PHPT patients in two European cohorts (20052014)

\begin{tabular}{llll}
\hline Feature & LAT & GER & $p$ \\
\hline No. of patients & 288 & 694 & \\
Mean age (years) \pm SD & $58.6 \pm 12.65$ & $58 \pm 13.98$ & NS \\
Sex (male/female) & $35 / 253$ & $134 / 560$ & 0.006 \\
Mean preoperative serum calcium $(\mathrm{mmol} / \mathrm{l}) \pm \mathrm{SD}$ & $2.89 \pm 0.34$ & $2.81 \pm 0.28$ & 0.01 \\
Mean preoperative serum parathormone (pg/ml) $\pm \mathrm{SD}$ & $324.56 \pm 403.93$ & $182.54 \pm 166.83$ & 0.001 \\
Nephrolithiasis (\%) & 30.2 & 28.2 & NS \\
\hline
\end{tabular}

LAT Pauls Stradins Clinical university hospital, Riga, Latvia; GER Lukas hospital, Neuss, Germany; SD standard deviation; NS not significant

Reference ranges: calcium 2.20-2.60 mmol/1; parathormone $17.00-72.00 \mathrm{pg} / \mathrm{ml}$ 
13.5-18.9) in GER group. Both these findings were present in $17.4 \%(95 \% \mathrm{CI}=13.4-22.2)$ of LAT vs $10.5 \%(95 \% \mathrm{CI}=$ 8.4-13.0) of GER patients.

PC was confirmed by postoperative histology in $6 / 288$ $(2.1 \%)$ LAT and 2/694 (0.3\%) GER patients. The difference was statistically significant; $p=0.004$. There was one male PC patient in LAT group but the remaining five LAT, and both GER patients were females. The demographic data, clinical features and results of IHC staining for $\mathrm{Ki}-67$ and parafibromin are displayed in Table 2. The mean age of PC diagnostics was $52.2 \pm 16.1$ years in LAT group. Due to the low number of cases, the mean age was not used to characterise the GER PC patients. In LAT cohort, 4/6 PC cases showed elevated preoperative $\mathrm{Ca}$ above $2.9 \mathrm{mmol} / \mathrm{l}$ in combination with high preoperative $\mathrm{PTH}>250 \mathrm{pg} / \mathrm{ml}$. The remaining LAT patients had either elevated Ca (1/6) or PTH (1/6). In GER group, the only pathological biochemical laboratory finding was elevated $\mathrm{Ca}>2.9 \mathrm{mmol} / \mathrm{l}$ in a single patient.

In both cohorts, $\mathrm{Ki}-67$ expression was observed in at least $5 \%$ of PC cells (Fig. 1a) except a single case showing proliferation fraction of $4.8 \%$. The highest proliferative activity was $22.7 \%$. IHC expression of parafibromin was invariably negative in all PC cases (Fig. 1b) contrasting to mostly positive staining in benign parathyroid tissues (Fig. 2; Table 3).

Further, we analysed the immunophenotype for Ki-67 and parafibromin expression in clinically distinct parathyroid lesions. The mean value of Ki-67 expression in PC was $10.6 \%$ (95\% CI=4.0-17.1) in LAT group vs 11.0 (95\% CI=0.023.5) in GER patients. The proliferation activity in parathyroid adenomas was statistically and biologically significantly lower, ranging from $1.6 \%(95 \% \mathrm{CI}=1.3-2.0)$ to $1.6 \%(0.7-$ 2.6) in respect to morphological and biochemical features (Table 3 ). To estimate the role of tumour heterogeneity regarding parafibromin expression, the proliferation activity by $\mathrm{Ki}$ 67 was also compared between PC and PA showing focal loss of parafibromin. However, PA manifesting parafibromin heterogeneity also had significantly lower proliferation activity than carcinomas, namely $2.2 \%(95 \% \mathrm{CI}=0.6-3.8)$ vs $10.6 \%$ (95\% CI=4.0-17.1) considering the larger cohort. The relevant data are shown in Table 4.

\section{Discussion}

Parathyroid carcinoma (PC) is a very rare endocrine entity, but highly aggressive form of PHPT. The frequency of PC among PHPT patients ranges widely between values less than $0.2 \%$ and exceeding $4 \%$, if the studies from North America and most of Europe are compared to those from Asia and Italy, respectively [20-24]. The rarity of this tumour embarrasses the genetic studies. Thus, it is not well proven, whether PC generally arises de novo or from pre-existing benign PA through the accumulation of genetic abnormalities [25]. There are some case reports describing PC on the background of parathyroid adenoma or hyperplasia, but these data are very scanty [26, 27]. Further, neither imaging nor clinical or laboratory findings can reliably predict PC course in cases lacking any evidence of metastasis, thus impairing both patient's care and reliability of epidemiological studies [28].

Regarding the PC frequency, significant differences were found between the assessed European PHPT cohorts as PC was diagnosed in $2.1 \%$ LAT but only in $0.3 \%$ GER patients. This could be explained by delayed diagnostics. However, adenoma-to-carcinoma progression has never been shown for PC. It also could be due to geographic variability or by selection bias in the patient referral for surgery. To test these hypotheses, we assessed the demographics, including the age structure, and the molecular characteristics including proliferation activity and loss of parafibromin, suggesting HRPT2 mutations. In addition, the possibility of discordant morphologic investigation was excluded by strict adherence to the diagnostic criteria described in the Materials and methods.

Historically, delayed presentation of PHPT was characteristic, including functional and structural lesions of the internal
Table 2 Demographic data, clinical features and immunohistochemical marker expression in parathyroid carcinoma

\begin{tabular}{|c|c|c|c|c|c|c|}
\hline & Age & Sex & Calcium (mmol/l) & Parathormone (pg/ml) & $\mathrm{Ki}-67^{\mathrm{a}}(\%)$ & Parafibromin $^{\mathrm{b}}$ \\
\hline \multirow[t]{6}{*}{ LAT } & 45 & Male & 3.76 & 1869.2 & 9.7 & neg \\
\hline & 57 & Female & 4.07 & 2031.1 & 8.3 & neg \\
\hline & 36 & Female & 4.20 & 2331.4 & 10.3 & neg \\
\hline & 66 & Female & 3.96 & 2176.3 & 22.7 & neg \\
\hline & 35 & Female & 3.03 & 575.2 & 4.8 & neg \\
\hline & 74 & Female & 3.04 & 1097.5 & 5.7 & neg \\
\hline \multirow[t]{2}{*}{ GER } & 67 & Female & 3.10 & 474.4 & 12.0 & neg \\
\hline & 52 & Female & 3.40 & 165.3 & 10.0 & neg \\
\hline
\end{tabular}

LAT Pauls Stradins Clinical university hospital, Riga, Latvia; GER Lukas hospital, Neuss, Germany; neg negative Reference ranges: calcium 2.20-2.60 mmol/1; parathormone $17.00-72.00 \mathrm{pg} / \mathrm{ml}$

${ }^{a}$ Percentage of positive cells

${ }^{\mathrm{b}}$ Expression as a categorical variable 
Fig. 1 Immunophenotype of the parathyroid carcinoma. a High proliferation activity by Ki- 67 . Immunoperoxidase (IP), anti-Ki67 (clone MIB-1), original magnification $(\mathrm{OM})$ 400×. b Complete absence of parafibromin. Note the presence of mitotic figure and enlarged nucleoli. IP, anti-parafibromin, OM $400 \times$

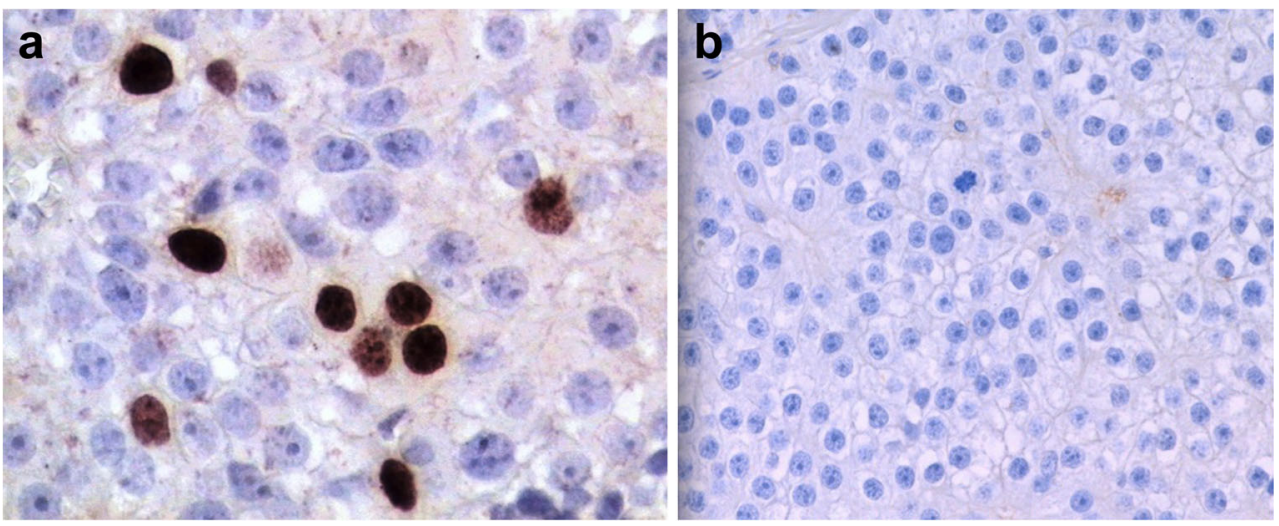

organs, nephrolithiasis, hypercalcaemic crisis, muscle weakness, pancreatitis or osteitis fibrosa cystica [29, 30]. Nowadays, the full-blown clinical picture has become rare in most PHPT cases but still can be observed in patients with fast growing parathyroid tumours such as PC. The rapid clinical progression of $\mathrm{PC}$ in the setting of predominantly clinical diagnostics of PHPT can lead to diagnostics of PC in earlier age than PA, as it was reported in former publications [31]. At present, the majority of patients are diagnosed before the typical PHPT picture occurs, and some may even lack clinical symptoms at the time of diagnosis [32]. The widespread availability of biochemical tests can lead to significantly improved diagnostics in older patients who frequently undergo testing for $\mathrm{Ca}$ in association with diagnostics and treatment of other concomitant diseases. Consequently, the epidemiological landscape of PC can now change to the predominance of patients older than 60 years.

We therefore questioned whether this difference in age distribution between PC and PA patients still persists. In our patient cohorts, including 288 LAT and 694 GER patients, no age difference was found (mean age, $58.6 \pm 12.65$ vs $58 \pm$ 13.98 years). Regarding PC, the age ranged widely (354 years), and the mean age was not significantly different from the general PHPT cohorts. Thus, a subfraction of PC patients still is diagnosed in young age influencing the mean age; and

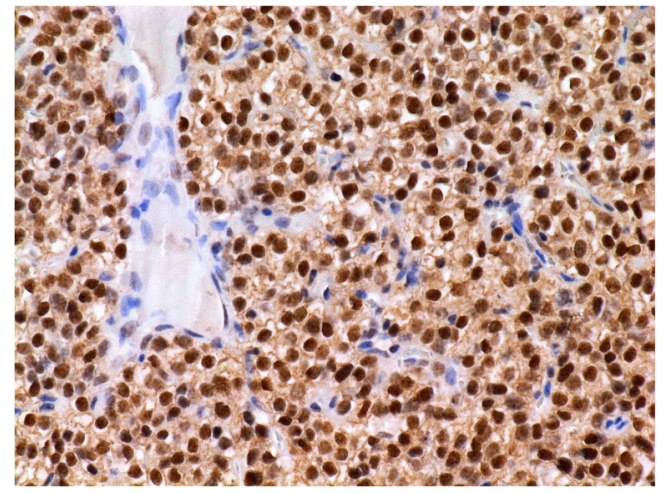

Fig. 2 Intense nuclear expression of parafibromin in parathyroid adenoma. Immunoperoxidase, anti-parafibromin, original magnification $400 \times$ aged persons also have been affected. The age analysis also does not support a difference in the time of PHPT diagnosis in the two European cohorts, which otherwise could explain the increased PC frequency among LAT patients. We neither found a difference in sex ratio between PC and PA patients as stated by other authors, who demonstrated a female predominance in PA but rather equal number of females and males in PC cohorts [33]. The predominance of females was shown in all our patient groups. However, higher female-tomale ratio was observed in LAT PHPT patients when compared to PHPT patients from GER (female-to-male ratio, 7:1 vs $4: 1)$.

Altogether, these demographic and clinical data support the independent development of PA and PC contrasting with the tumourigenesis in the other organs such as the large bowel. However, the theory of unrelated genesis of parathyroid tumours has been supported by the assessment of the underlying mutations in PA and PC as well as gene expression by whole genome sequencing [34].

Since a progression of PA to PC has been suggested in some earlier publications [35, 36], higher $\mathrm{Ca}$ as well as $\mathrm{PTH}$ levels in LAT cohort when compared to GER patients with PHPT, in association with higher PC frequency, could have been interpreted as an evidence of tumour progression. Additional to the previously described age structure and literaturebased contradictions to the hypothesis of tumour progression, the experience in MEN1 and MEN2 patients does not demonstrate adenoma-to-carcinoma sequence. The genetic analysis seldom demonstrates MEN1 mutations in PC. As few as ten patients with MEN1 and MEN2 syndromes (seven and three, respectively) have ever been shown to suffer from malignant parathyroid tumours [37]. Thus, $\mathrm{PC}$ is surprisingly rare in MEN1 patients, despite the fact that PHPT in MEN1 patients can be detected early and despite the high recurrence rate of PHPT even after effective primary surgery [38].

With increasing numbers of HPT-JT families the number of PC patients will increase. Other sporadic and familial forms of PHPT however will not change the incidence of PC.

Therefore, with exception of PHPT and HPT-JT families, PC occurrence lacks any correlation to occurrence of other 
Table 3 Immunophenotype of parathyroid adenomas in relation to distinct clinical features

\begin{tabular}{|c|c|c|c|c|}
\hline \multirow[t]{2}{*}{ Target group } & \multicolumn{2}{|l|}{ Ki-67 } & \multicolumn{2}{|l|}{ Parafibromin } \\
\hline & Mean $\pm \mathrm{SD}$ & $95 \% \mathrm{CI}$ & Frequency $(\%)$ & $95 \% \mathrm{CI}$ \\
\hline Adenoma (atypical morphology, preoperative $\mathrm{Ca}>2.9 \mathrm{mmol} / \mathrm{l}$, preoperative $\mathrm{PTH}>250 \mathrm{pg} / \mathrm{ml}$ ) & $1.6 \pm 1.00$ & $1.3-2.0$ & 97.5 & $86.0-100.0$ \\
\hline Adenoma (preoperative $\mathrm{Ca}<2.9 \mathrm{mmol} / \mathrm{l}$, preoperative $\mathrm{PTH}<250 \mathrm{pg} / \mathrm{ml}$ ) & $1.6 \pm 1.53$ & $0.7-2.6$ & 100.0 & $89.1-100.0$ \\
\hline
\end{tabular}

$S D$ standard deviation, $C I$ confidence interval, $C a$ serum calcium level, $P T H$ serum parathormone level

Reference ranges: calcium 2.20-2.60 mmol/l; parathormone $17.00-72.00 \mathrm{pg} / \mathrm{ml}$

patients with sporadic or familial PHPT. This assumption can be generalised and also fits for our LAT and GER patient cohorts. However, germline mutation of HRPT2 gene is responsible for the autosomal dominant HPT-JT syndrome, manifesting as multiple benign and/or malignant parathyroid neoplasms as well as uterine and renal tumours and ossifying fibromas of the jaw bones [25, 36]. Germline HRPT2 mutations are also found in patients with familial isolated hyperparathyroidism and in up to $20 \%$ of PC patients who have been primarily classified as sporadic [25], while somatic HRPT2 mutations are almost exclusively found in up to $77 \%$ of sporadic PC and in less than $1 \%$ of sporadic PA $[4,6,7]$.

Parafibromin represents the protein product of HRPT2. It is involved in cell transcription, differentiation, proliferation and apoptosis. Although the exact way by which this protein increases the malignant potential of PC remains unclear, it is known to inhibit cyclin D1, which stimulates parathyroid cell growth [12, 39]. In our two European cohorts, all PC patients showed diffuse loss of parafibromin by IHC staining. These data seem surprisingly homogeneous but are in accordance with other publications in this field. Cohorts with higher number of PC patients did present loss of parafibromin staining in approximately $60-100 \%[3,11,12,25,40,41]$. Some of these differences can be attributable to variable definitions of

Table 4 Descriptive statistics of proliferation activity by Ki-67 expression in parathyroid tumours showing diffuse vs focal loss of parafibromin

\begin{tabular}{|c|c|c|c|}
\hline \multirow[t]{2}{*}{ Target group } & \multicolumn{2}{|l|}{ Ki-67 } & \multirow{2}{*}{$\begin{array}{l}\text { Parafibromin } \\
\text { Expression }\end{array}$} \\
\hline & Mean \pm SD & $95 \% \mathrm{CI}$ & \\
\hline \multicolumn{4}{|c|}{ Parathyroid carcinoma } \\
\hline LAT $(n=6)$ & $10.6 \pm 6.23$ & $4.0-17.1$ & Diffuse loss $(6 / 6)$ \\
\hline GER $(n=2)$ & $11.0 \pm 1.40$ & $0-23.5$ & Diffuse loss $(2 / 2)$ \\
\hline \multicolumn{4}{|c|}{ Atypical adenoma $+\mathrm{Ca}>2.9 \mathrm{mmol} / \mathrm{l}$ and $\mathrm{PTH}>250 \mathrm{pg} / \mathrm{ml}$} \\
\hline LAT $(n=7)$ & $2.2 \pm 1.70$ & $0.6-3.8$ & Focal loss $(7 / 7)$ \\
\hline GER $(n=3)$ & $1.1 \pm 0.53$ & $0.6-1.6$ & Focal loss $(3 / 3)$ \\
\hline
\end{tabular}

$S D$ standard deviation; $C I$ confidence interval; $n$ absolute number; $L A T$ Pauls Stradins Clinical university hospital, Riga, Latvia; GER Lukas hospital, Neuss, Germany

Reference ranges: calcium $2.20-2.60 \mathrm{mmol} / \mathrm{l}$; parathormone 17.00 $72.00 \mathrm{pg} / \mathrm{ml}$ malignant behaviour in parathyroid tumours that can be limited to histologic interpretation only or to clinical follow-up data. In our study, parafibromin expression in so-called atypical PA varied significantly showing either diffuse positivity or focal loss of expression.

A study by Quinn et al. regarding the utility of parafibromin and Ki-67 in the differential diagnostics of parathyroid tumours resulted in the conclusion that loss of parafibromin expression and extent of $\mathrm{Ki}-67$ staining has not been shown to distinguish between PC and atypical adenoma [42]. Those findings are contrary to our data confirming higher proliferation fraction by Ki-67 expression and invariable diffuse loss of parafibromin in PC. Certain other authors also have reported high diagnostic value of parafibromin in the diagnostics of parathyroid carcinoma [15-17]. The study by Witteveen et al. demonstrated a germline and/or somatic HRPT2 mutation in only four of the $23 \mathrm{PC}$ patients $(17 \%)$. These four patients developed a local recurrence and/or distant metastasis during follow-up, suggesting that other factors may also have role in the tumorigenesis of PC [12].

Recently, further studies with new generation genomic sequencing enlightened the genomic landscape of recurring sporadic $\mathrm{PC}$ and depicted multiple somatic mutations in other genes than HRPT2. Some single nucleotide point mutations were located to well-known genes such as MTOR, MLL2 and $C D K N 2 C$. Loss of function was found in PIK3CA gene, and truncating mutations were demonstrated in $C D K N 2 C$ and THRAP3 genes. The mutation in PIK3CA encoding for a catalytic subunit of PI3K alters the phosphoinositol pathway, while $C D N K 2 C$ mutations impair the inhibition of cyclindependent kinases 4 and 6 [43] that stimulate cellular growth. Future genetic investigations have to confirm these data and may lead to specific fingerprints of genetic alterations in PC resulting in molecular classification that will replace the present histology and IHC.

We also analysed Ki-67 expression in benign adenomas concentrating on different preoperative biochemical features including $\mathrm{Ca}$ and PTH serum levels. Here, we did not find any statistically significant difference in Ki-67 expression between the subgroups of adenomas (Table 4). The lack of correlation between proliferation activity and the functional tumour manifestations also supports the applicability of $\mathrm{Ki}-67 \mathrm{IHC}$ in the differential diagnostics of parathyroid tumours. 
Since histologic features and clinical behaviour of parathyroid tumours sometimes differ substantially in the follow-up of patients with PC (recurrence and metastasis in histologically seemingly benign tumours as well as long-standing cure of PC by surgery alone), an additional measurement still seems necessary. Whether detection of genetic alteration patterns may fulfil these expectations and will be able to differentiate between benign and malignant parathyroid tumours, at present, is still unknown.

Focusing on the histology as the predictor of clinical course in PC, several morphologic evaluation systems have been reported. Those described by Schantz and Castleman are the most widely used, when PC have to be separated from benign parathyroid tumours [44]. Metastasis and clear-cut invasion remain among the cardinal properties of malignant tumours. The additional morphological features include capsular invasion, presence of trabecular patterns and mitotic figures as well as the presence of fibrous bands. In our study, we also based PC diagnosis on the cardinal tumour signs. However, it still is important to consider the overall clinical picture rather than any single histopathological criteria, when future outcome is prospectively assumed [45].

Thus, significant geographic differences in the PC frequency among the European PHPT patients have shown in the present study. As the age structure and molecular characteristics of PC in both cohorts are similar, biases in patient referral for surgery may be considered as the main underlying cause. Reliable and unified diagnostics should be a cornerstone of the scientific evaluation of rare diseases. The increased proliferation fraction and loss of parafibromin are important molecular features of parathyroid carcinoma that are equally applicable to both tested cohorts. The future studies should elaborate novel morphological and molecular diagnostic tests, considering also the markers explored in the present study.

Limitations of our study are the retrospective analysis of data, lack of epidemiological information concerning the prevalence of PC in Latvian and German population and the low number of patients with PC.

\section{Conclusions}

PC frequency can range significantly between the two European cohorts. The differences can be attributable to selection bias of patients referred for surgery and are not caused by discordant definition of malignant parathyroid histology.

The identification of the parafibromin, encoded by HRPT2 gene, has provided an important insight in the molecular pathogenesis of PC. Total loss of parafibromin staining and increased proliferation fraction by Ki-67 are valuable adjuncts that may help in differentiating between atypical adenomas and PC.

\section{Authors' contributions}

- Study conception and design: Arturs Ozolins, Peter E. Goretzki, Zenons Narbuts and Ilze Strumfa

- Acquisition of data: Arturs Ozolins, Zane Visnevska, Aycan Akca, Denis Wirowski*, Zane Simtniece, Ilze Strumfa and Peter E. Goretzki

- Analysis and interpretation of data: Arturs Ozolins, Andrejs Vanags, Zane Simtniece, Zenons Narbuts, Aycan Akca and Peter E. Goretzki

- Drafting of manuscript: Arturs Ozolins, Zenons Narbuts, Ilze Strumfa and Peter E. Goretzki

- Critical revision of manuscript: Arturs Ozolins, Zenons Narbuts, Andrejs Vanags, Ilze Strumfa, Janis Gardovskis and Peter E. Goretzki

Compliance with ethical standards The study was performed in accordance with the Declaration of Helsinki and permission of the Committee of Ethics, Riga Stradins University (No. E-9(2), issued on May 5th, 2014). The present work was carried out within the frames of scientific project Nr. 2013/0004/1DP/1.1.1.2.0/13/APIA/VIAA/ 020, supported by the European Social Fund (ESF). This article does not contain any studies with human participants or animals performed by any of the authors.

Conflicts of interest None.

Open Access This article is distributed under the terms of the Creative Commons Attribution 4.0 International License (http:// creativecommons.org/licenses/by/4.0/), which permits unrestricted use, distribution, and reproduction in any medium, provided you give appropriate credit to the original author(s) and the source, provide a link to the Creative Commons license, and indicate if changes were made.

\section{References}

1. Cetani F, Banti C, Pardi E, Borsari S, Viacava P, Miccoli P, Torregrossa L, Basolo F, Pelizzo MR, Rugge M, Pennelli G, Gasparri G, Papotti M, Volante M, Vignali E, Saponaro F, Marcocci C (2013) CDC73 mutational status and loss of parafibromin in the outcome of parathyroid cancer. Endocrine connections 2(4):186-195. doi:10.1530/EC-13-0046

2. Allen ME, Semrad A, Yang AD, Martinez SR (2013) Parathyroid carcinoma survival: improvements in the era of intact parathyroid hormone monitoring? Rare tumors 5(1), e12. doi:10.4081/rt.2013.e12

3. Wilkins BJ, Lewis JS Jr (2009) Non-functional parathyroid carcinoma: a review of the literature and report of a case requiring extensive surgery. Head Neck Pathol 3(2):140-149. doi:10.1007/ s12105-009-0115-4

4. Witteveen JE, Haak HR, Kievit J, Morreau H, Romijn JA, Hamdy NA (2010) Challenges and pitfalls in the management of parathyroid carcinoma: 17-year follow-up of a case and review of the literature. Hormones \& cancer 1(4):205-214. doi:10.1007/ s12672-010-0042-6

5. Hundahl SA, Fleming ID, Fremgen AM, Menck HR (1999) Two hundred eighty-six cases of parathyroid carcinoma treated in the U.S. between 1985-1995: a National Cancer Data Base Report. The American College of Surgeons Commission on Cancer and the American Cancer Society. Cancer 86(3):538-544 
6. Rawat N, Khetan N, Williams DW, Baxter JN (2005) Parathyroid carcinoma. Br J Surg 92(11):1345-1353. doi:10.1002/bjs.5182

7. Lihara M, Okamoto T, Suzuki R, Kawamata A, Nishikawa T, Kobayashi M, Obara T (2007) Functional parathyroid carcinoma: long-term treatment outcome and risk factor analysis. Surgery 142(6):936-943. doi:10.1016/j.surg.2007.09.014, discussion 943 e931

8. Thompson L (2006) World Health Organization classification of tumours: pathology and genetics of head and neck tumours. Ear Nose Throat J 85(2):74

9. Koea JB, Shaw JH (1999) Parathyroid cancer: biology and management. Surg Oncol 8(3):155-165

10. Kleinpeter KP, Lovato JF, Clark PB, Wooldridge T, Norman ES, Bergman S, Perrier ND (2005) Is parathyroid carcinoma indeed a lethal disease? Ann Surg Oncol 12(3):260-266. doi:10.1245/ASO. 2005.03.036

11. Gill AJ (2014) Understanding the genetic basis of parathyroid carcinoma. Endocr Pathol 25(1):30-34. doi:10.1007/s12022-0139294-3

12. Witteveen JE, Hamdy NA, Dekkers OM, Kievit J, van Wezel T, Teh BT, Romijn JA, Morreau H (2011) Downregulation of CASR expression and global loss of parafibromin staining are strong negative determinants of prognosis in parathyroid carcinoma. Mod Pathol 24(5):688-697. doi:10.1038/modpathol.2010.236

13. Lloyd RV, Carney JA, Ferreiro JA, Jin L, Thompson GB, Van Heerden JA, Grant CS, Wollan PC (1995) Immunohistochemical analysis of the cell cycle-associated antigens Ki-67 and retinoblastoma protein in parathyroid carcinomas and adenomas. Endocr Pathol 6(4):279-287

14. Juhlin CC, Hoog A (2010) Parafibromin as a diagnostic instrument for parathyroid carcinoma-lone ranger or part of the posse? Int $\mathrm{J}$ Endocrinol 2010:324964. doi:10.1155/2010/324964

15. Kruijff S, Sidhu SB, Sywak MS, Gill AJ, Delbridge LW (2014) Negative parafibromin staining predicts malignant behavior in atypical parathyroid adenomas. Ann Surg Oncol 21(2):426-433. doi:10. 1245/s10434-013-3288-8

16. Kim HK, Oh YL, Kim SH, Lee DY, Kang HC, Lee JI, Jang HW, Hur KY, Kim JH, Min YK, Chung JH, Kim SW (2012) Parafibromin immunohistochemical staining to differentiate parathyroid carcinoma from parathyroid adenoma. Head Neck 34(2): 201-206. doi:10.1002/hed.21716

17. Wang O, Wang CY, Shi J, Nie M, Xia WB, Li M, Jiang Y, Guan H, Meng XW, Xing XP (2012) Expression of Ki-67, galectin-3, fragile histidine triad, and parafibromin in malignant and benign parathyroid tumors. Chin Med J 125(16):2895-2901

18. Guarnieri V, Battista C, Muscarella LA, Bisceglia M, de Martino D, Baorda F, Maiello E, D'Agruma L, Chiodini I, Clemente C, Minisola S, Romagnoli E, Corbetta S, Viti R, Eller-Vainicher C, Spada A, Iacobellis M, Malavolta N, Carella M, Canaff L, Hendy GN, Cole DE, Scillitani A (2012) CDC73 mutations and parafibromin immunohistochemistry in parathyroid tumors: clinical correlations in a single-centre patient cohort. Cell Oncol 35(6):411422. doi:10.1007/s13402-012-0100-x

19. Altman DG (2000) ROC curves and confidence intervals: getting them right. Heart 83(2):236

20. Sadler C, Gow KW, Beierle EA, Doski JJ, Langer M, Nuchtern JG, Vasudevan SA, Goldfarb M (2014) Parathyroid carcinoma in more than 1,000 patients: a population-level analysis. Surgery $156(6)$ : 1622-1629. doi:10.1016/j.surg.2014.08.069, discussion 16291630

21. Lumachi F, Basso SM, Basso U (2006) Parathyroid cancer: etiology, clinical presentation and treatment. Anticancer Res 26(6C): 4803-4807

22. Lee YS, Hong SW, Jeong JJ, Nam KH, Chung WY, Chang HS, Park CS (2010) Parathyroid carcinoma: a 16-year experience in a single institution. Endocr J 57(6):493-497
23. Iacobone M, Lumachi F, Favia G (2004) Up-to-date on parathyroid carcinoma: analysis of an experience of 19 cases. J Surg Oncol 88(4):223-228. doi:10.1002/jso.20152

24. Zhao L, Liu JM, He XY, Zhao HY, Sun LH, Tao B, Zhang MJ, Chen X, Wang WQ, Ning G (2013) The changing clinical patterns of primary hyperparathyroidism in Chinese patients: data from 2000 to 2010 in a single clinical center. J Clin Endocrinol Metab 98(2):721-728. doi:10.1210/jc.2012-2914

25. Costa-Guda J, Arnold A (2014) Genetic and epigenetic changes in sporadic endocrine tumors: parathyroid tumors. Mol Cell Endocrinol 386(1-2):46-54. doi:10.1016/j.mce.2013.09.005

26. Murayama T, Kawabe K, Tagami M (1977) A case of parathyroid carcinoma concurred with hyperplasia: an electron microscopic study. J Urol 118(1 Pt 1):126-127

27. Desch CE, Arsensis G, Woolf PD, May AG, Amatruda JM (1984) Parathyroid hyperplasia and carcinoma within one gland. Am J Med 77(1):131-134

28. Karakas E, Muller HH, Lyadov VK, Luz S, Schneider R, Rothmund M, Bartsch DK, Schlosser K (2012) Development of a formula to predict parathyroid carcinoma in patients with primary hyperparathyroidism. World J Surg 36(11):2605-2611. doi:10. 1007/s00268-012-1707-9

29. Belcher R, Metrailer AM, Bodenner DL, Stack BC Jr (2013) Characterization of hyperparathyroidism in youth and adolescents: a literature review. Int J Pediatr Otorhinolaryngol 77(3):318-322. doi:10.1016/j.ijporl.2012.12.008

30. Hyperparathyroidism AATFoP (2005) The American Association of Clinical Endocrinologists and the American Association of Endocrine Surgeons position statement on the diagnosis and management of primary hyperparathyroidism. Endocr Pract 11(1):49 54. doi:10.4158/EP.11.1.49

31. Bilezikian JP, Brandi ML, Eastell R, Silverberg SJ, Udelsman R, Marcocci C, Potts JT Jr (2014) Guidelines for the management of asymptomatic primary hyperparathyroidism: summary statement from the Fourth International Workshop. J Clin Endocrinol Metab 99(10):3561-3569. doi:10.1210/jc.2014-1413

32. Bilezikian JP, Silverberg SJ, Shane E, Parisien M, Dempster DW (1991) Characterization and evaluation of asymptomatic primary hyperparathyroidism. J Bone Miner Res Off J Am Soc Bone Miner Res 6(Suppl 2):S85-S89. doi:10.1002/jbmr.5650061419, discussion S121-124

33. Talat N, Schulte KM (2010) Clinical presentation, staging and longterm evolution of parathyroid cancer. Ann Surg Oncol 17(8):2156 2174. doi:10.1245/s10434-010-1003-6

34. Oltmann SC, Rajaei MH, Sippel RS, Chen H, Schneider DF (2014) Primary hyperparathyroidism across the ages: presentation and outcomes. J Surg Res 190(1):185-190. doi:10.1016/j.jss.2014.04.010

35. Levin KE, Galante M, Clark OH (1987) Parathyroid carcinoma versus parathyroid adenoma in patients with profound hypercalcemia. Surgery 101(6):649-660

36. Gill AJ, Clarkson A, Gimm O, Keil J, Dralle H, Howell VM, Marsh DJ (2006) Loss of nuclear expression of parafibromin distinguishes parathyroid carcinomas and hyperparathyroidism-jaw tumor (HPTJT) syndrome-related adenomas from sporadic parathyroid adenomas and hyperplasias. Am J Surg Pathol 30(9):1140-1149. doi:10. 1097/01.pas.0000209827.39477.4f

37. Carling T, Udelsman R (2005) Parathyroid surgery in familial hyperparathyroid disorders. J Intern Med 257(1):27-37. doi:10. 1111/j.1365-2796.2004.01428.x

38. Machens A, Lorenz K, Dralle H (2013) Peak incidence of pheochromocytoma and primary hyperparathyroidism in multiple endocrine neoplasia 2: need for age-adjusted biochemical screening. J Clin Endocrinol Metab 98(2):E336-E345. doi:10.1210/jc.20123192

39. Newey PJ, Bowl MR, Cranston T, Thakker RV (2010) Cell division cycle protein 73 homolog (CDC73) mutations in the 
hyperparathyroidism-jaw tumor syndrome (HPT-JT) and parathyroid tumors. Hum Mutat 31(3):295-307. doi:10.1002/humu.21188

40. Diaconescu MR, Glod M, Costea I, Grigorovici M, Diaconescu S (2015) Clinicopathological phenotype of parathyroid carcinoma: therapeutic and prognostic aftermaths. Chirurgia 110(1):66-71

41. Weinstein LS, Simonds WF (2003) HRPT2, a marker of parathyroid cancer. N Engl J Med 349(18):1691-1692. doi:10.1056/ NEJMp038159

42. Quinn CE, Healy J, Lebastchi AH, Brown TC, Stein JE, Prasad ML, Callender GG, Carling T, Udelsman R (2015) Modern experience with aggressive parathyroid tumors in a high-volume New England referral center. J Am Coll Surg 220(6):1054-1062. doi:10. 1016/j.jamcollsurg.2014.10.007
43. Kasaian K, Wiseman SM, Thiessen N, Mungall KL, Corbett RD, Qian JQ, Nip KM, He A, Tse K, Chuah E, Varhol RJ, Pandoh P, McDonald H, Zeng T, Tam A, Schein J, Birol I, Mungall AJ, Moore RA, Zhao Y, Hirst M, Marra MA, Walker BA, Jones SJ (2013) Complete genomic landscape of a recurring sporadic parathyroid carcinoma. J Pathol 230(3):249-260. doi:10.1002/path.4203

44. Schantz A, Castleman B (1973) Parathyroid carcinoma. A study of 70 cases. Cancer 31(3):600-605

45. Betea D, Potorac I, Beckers A (2015) Parathyroid carcinoma: challenges in diagnosis and treatment. Ann Endocrinol 76(2):169-177. doi:10.1016/j.ando.2015.03.003 